\title{
Dopaminergic drugs alter beta coherence during motor imagery and motor execution in healthy adults
}

\author{
Drogas dopaminérgicas alteram a coerência beta durante \\ a imagética motora e a execução motora em adultos saudáveis
}

Danielle APRIGIO',2, Guaraci Ken TANAKA',2, Juliana BITTENCOURT $T^{2,3}$, Mariana GONGORA ${ }^{3,4}$, Silmar TEIXEIRA ${ }^{1,5}$, Mauricio CAGY ${ }^{6}$, Henning BUDDE $7,8,9$, Marco ORSIN/10,11, Pedro RIBEIRO ${ }^{1,2,12}$, Bruna VELASQUES 1,2,4

\begin{abstract}
Background: Motor Imagery (MI) represents the cognitive component of the movement and recruits dopaminergic systems. Objective: To investigate the role of dopaminergic system through the action of methylphenidate and risperidone over beta coherence during execution, action observation and motor imagery. Methods: Electroencephalography (EEG) data were recorded before and after the substance intake. For statistical analysis, a three-way ANOVA was used to identify changes in beta coherence induced by the group, task and the moment variables. Statistical significance was set at $\mathrm{p} \leq 0.007$. Results: We found a main effect for group for $\mathrm{C} 3 / \mathrm{CZ}$, and a main effect for task for CZ/C4 pairs of electrodes. Furthermore, significant differences were found in the post-drug administration between groups for C3/CZ pair of electrodes, and between task for C4/CZ pair of electrodes. Conclusion: The administration of methylphenidate and risperidone was able to produce electrocortical changes of the cortical central regions, even when featuring antagonistic effects on the dopaminergic pathways. Moreover, the execution task allowed beta-band modulation increase.
\end{abstract}

Keywords: electroencephalography; beta rhythm; methylphenidate; risperidone; motor imagery.

\section{RESUMO}

Introdução: A imagética motora (IM) representa o componente cognitivo do movimento e recruta os sistemas dopaminérgicos. Objetivo: Investigar o papel do sistema dopaminérgico por meio da ação do metilfenidato e da risperidona sobre a coerência em beta durante a execução, observação de ação e imagética motora. Métodos: Os dados de eletroencefalografia (EEG) foram registrados antes e depois da ingestão das substâncias. Para a análise estatística, uma ANOVA de três vias foi utilizada para identificar mudanças na coerência beta induzidas pelas variáveis grupo, tarefa e momento. A significância estatística foi estabelecida em $p \leq 0,007$. Resultados: Encontramos um efeito principal para o grupo C3/CZ e um efeito principal para a tarefa nos pares de eletrodos CZ/C4. Além disso, diferenças significativas foram encontradas após a administração da droga entre os grupos para o par de eletrodos C3/CZ e entre tarefa para o par de eletrodos C4/CZ. Conclusão: A administração de metilfenidato e risperidona foi capaz de produzir alterações eletrocorticais das regiões somatomotoras, mesmo apresentando efeitos antagônicos nas vias dopaminérgicas. Além disso, a tarefa de execução provocou maior modulação da banda beta.

Palavras-chave: eletroencefalografia; ritmo beta; metilfenidato; risperidona; imagética motora.

'Universidade Federal do Rio de Janeiro, Instituto de Psiquiatria, Laboratório de Neurofisiologia e Neuropsicologia da Atenção, Rio de Janeiro RJ, Brazil. ${ }^{2}$ Instituto de Neurociências Aplicadas, Rio de Janeiro RJ, Brazil.

${ }^{3}$ Universidade Veiga de Almeida, Rio de Janeiro RJ, Brazil.

«Universidade Federal do Rio de Janeiro, Instituto de Psiquiatria, Laboratório de Mapeamento Cerebral e Integração Sensoriomotora, Rio de Janeiro RJ, Brazil.

${ }^{5}$ Universidade Federal do Piauí, Laboratório de Plasticidade e Mapeamento Cerebral, Parnaíba PI, Brazil.

${ }^{6}$ Universidade Federal do Rio de Janeiro, Programa de Engenharia Biomédica, Rio de Janeiro RJ, Brazil.

'Lithuanian Sports University (LSU), Kaunas, Lithuania.

${ }^{8}$ Faculty of Human Sciences, Medical School Hamburg, Hamburg, Germany.

${ }^{9}$ Reykjavik University, Sport Science, Reykajvik, Iceland

10Universidade de Vassouras, Rio de Janeiro RJ, Brazil.

${ }^{11}$ Universidade Iguaçu, Rio de Janeiro RJ, Brazil.

${ }^{12}$ Universidade Federal do Rio de Janeiro, Escola de Educação Física e Desporto, Departamento de Biociências, Rio de Janeiro RJ, Brazil. Danielle APRIGIO (ID) https://orcid.org/0000-0001-5970-3497; Guaraci Ken TANAKA (iD https://orcid.org/0000-0001-5222-0513;

Juliana BITTENCOURT (iD) https://orcid.org/0000-0003-1959-6345; Mariana GONGORA (iD https://orcid.org/0000-0001-9382-9958;

Silmar TEIXEIRA (iD) https://orcid.org/0000-0002-9240-1228; Mauricio CAGY (iD https://orcid.org/0000-0002-6488-842X;

Henning BUDDE (iD) https://orcid.org/0000-0003-3526-0569; Marco ORSINI ID https://orcid.org/0000-0002-8948-3955;

Pedro RIBEIRO (iD https://orcid.org/0000-0001-8270-3663; Bruna VELASQUES (iD https://orcid.org/0000-0001-9363-8932

Correspondence: Danielle Aprigio; Av. Venceslau Brás, 71/Fundos - Botafogo; 22290-140 Rio de Janeiro RJ, Brazil; E-mail: danyaprigio@gmail.com

Conflict of interest: There is no conflict of interest to declare.

Received 03 July 2019; Received in final form 07 November 2019. 
Every motor action is composed by motor and cognitive contributions. In the field of human motor cognition, researchers realized that the motor action involves an internal/cognitive stage ${ }^{1}$. In this way, the mental simulation of movements is a cognitive state ${ }^{2}$. The Motor Imagery (MI) can be defined as a dynamic process, in which the subject evokes the motor planning of a determined action and actively follows their unfolding without executing it $^{3}$. Researchers argue that MI of a specific movement works with the same neural mechanisms used during a motor execution ${ }^{4,5}$. Therefore, this variation can be identified by the quantitative electroencephalography (qEEG) $)^{6-8}$. Beta band $(12-30 \mathrm{~Hz}$ ) oscillations seem to originate largely in the primary motor cortex, and this activity has been associated with the movement control and sensorimotor integration processes ${ }^{5,9}$.

The coherence function is a measure that can be used to identify electrocortical alterations caused by movements ${ }^{10}$. This function has also been used to recognize the relation in the electrical activity of the brain between two regions, which is useful to observe the connectivity between them ${ }^{11}$. Literature demonstrates that the beta band coherence increases with higher accuracy during motor task execution ${ }^{9}$. Besides that, processes that involve the mental simulation of actions have been consistently associated to a decrease of beta band oscillations over the sensorimotor regions ${ }^{6,8,12}$. Most research has shown that the frontal, somatomotor and parietal regions are involved in movement planning, but little is known about how these regions interact during a mental simulation of movement ${ }^{4,5,13}$. Moreover, it is not clear yet if drugs that modulate the dopaminergic circuit could influence this action.

Antipsychotic and psychostimulant drugs are known for their typical effects over the $\mathrm{qEEG}^{14}$. The antipsychotic risperidone, antagonist of dopamine and serotonin receptors, in a small dose (0.5-2 $\mathrm{mg})$, seems to be useful in the reduction of psychotic symptoms and behavioral disturbances, with anticholinergic effects. Changes as dyskine$\mathrm{sia}^{15}$ and motor fluctuations can also be found in long-term therapies ${ }^{15}$. On the other hand, methylphenidate acts with the blockage of catecholamine reuptake on the pre-synaptic neurons, with more availability of these substances on the synaptic cleft, mainly over the reticular system, which activates the brainstem and brain cortex ${ }^{16}$. The motor cortex is sensitive to the effects of methylphenidate, increasing the release and reutilization of dopamine in this area. Hence, methylphenidate helps in self-regulatory control of the motor functions, improving motor execution ${ }^{17}$.

On the other hand, MI has been associated to the rehabilitation of patients that present neurological sequels, which seems to be enough to provoke plastic modulation of neural circuits, and improve the motor learning and performance during the rehabilitation ${ }^{3}$. This leads us to the question: would the association of MI to the pharmacological cognitive improvement caused by a cognitive enhancer be able to modify the cortical activity and improve the cognition?
We hypothesize that methylphenidate, a dopamine agonist, will provoke a higher coupling between the areas, suggesting higher somatosensory participation during movement execution, imagination, and observation. In contrast, we suppose that risperidone, a dopamine antagonist, will impair these movements showing a lower coherence between areas and demonstrating a coupling reduction.

The aim of the present study is to investigate the influence of $10 \mathrm{mg}$ of methylphenidate and $2 \mathrm{mg}$ of risperidone over beta coherence during the motor imagery, execution and observation of a movement. Specifically, we observed pairs of electrodes over the frontal (F3/Fz, F3/F4 and F4/Fz), somatomotor $(\mathrm{C} 3 / \mathrm{Cz}, \mathrm{C} 3 / \mathrm{C} 4$ and $\mathrm{C} 4 / \mathrm{Cz})$, and parietal $(\mathrm{P} 3 / \mathrm{Pz}, \mathrm{P} 3 / \mathrm{P} 4$ and $\mathrm{P} 4 / \mathrm{Pz})$ areas.

\section{METHODS}

\section{Sample}

Fifteen healthy subjects ( 4 men and 11 women, mean age 29.0 years; $\mathrm{SD} \pm 5.3$ ), all of them right-handed, according to the Edinburgh Inventory ${ }^{18}$, participated in the experiment. Subjects reported no history of cognitive or physical deficits, and no use of any psychoactive or psychotropic substances. We applied the Revised Movement Imagery Questionnaire (MIQ-R) to each participant to determine the ability for motor imagery reproduction ${ }^{19,20}$. The score should be less than 15 , which consisted in the real, visual imagery and kinesthetic implementation of simple motor tasks. All participants responded anamnesis to identify any subject who would not meet the study pre-requisites. Prior to the experiment, they were asked to sign an informed consent, which described the objectives of the experiment and the experimental procedure. The study was approved by the Ethics Committee of Universidade Federal do Rio de Janeiro (IPUB/UFRJ).

\section{Experimental procedure}

The randomized, double-blind experiment took place in a light and sound-attenuated room to minimize the sensory interference during data collection. All subjects were instructed to perform three visits to the research lab with at least one-week interval between them. At each visit, the subject would ingest one of the following capsules: $500 \mathrm{mg}$ starch (placebo), $2 \mathrm{mg}$ risperidone or $10 \mathrm{mg}$ methylphenidate. During the first visit, subjects were instructed to fill out the MIQ-R, as well as the Edinburgh Inventory and the informed consent form, under guidance and supervision. After that, subjects sat comfortably in a chair, positioned $45 \mathrm{~cm}$ away from a computer, to execute the experimental tasks. EEG data were recorded before, during and after the tasks. Before the start and the end of tasks, the individual was asked to rest for 3 minutes with their eyes opened. During the experiment, the subject performed three distinct 
tasks: execution, action observation and motor imagery of finger movement. During the execution task, the subject had to flex and extend the right index finger whenever a trigger stimulus appeared. The stimulus was a yellow square, that lasted (1) second, with a four-second (4) interval between the stimuli. During the interval, the screen was turned off. An accelerometer was used to identify the finger movement. The action observation task involved watching a video of the same movement, and the motor imagery task was imagining the flexion and extension of the index finger movement. During this task, a warning marker, a green circle, appeared on the screen for a period of one second (1); then, the main marker represented by a 10-second yellow square appeared indicating the time, in which the subject should be thinking about the movement. To determine the end of the task, the screen turns off for 0.5 seconds, and a red circle appears as a final marker for 0.5 seconds. Each task was performed 12 times, 6 times before and 6 times after the drug intake. Moreover, each time was composed by two trials, set up in a randomized order. The time interval for task repetition after drug intake was one hour and thirty minutes. For each trial, 15 different stimuli were presented to the participants (Figure 1). It is important to emphasize that, during the motor imagery task, participants were instructed to keep their attention to the start marker, which would appear in the screen, as well as to the use of visual MI strategy, on the third-person perspective. Participants were instructed to avoid any movement (i.e., eye blink, head or member movements) during the experimental procedure to minimize muscular artifacts during the EEG recordings.

\section{Data acquisition}

The electroencephalographic signal was recorded through the 20-channel BrainNet (BNT36 - EMSA system), in addition to the ERP Acquisition program developed by the Neurophysiology and Neuropsychology of Attention Laboratory. Its configuration uses $60 \mathrm{~Hz}$ Notch digital filtering, with high-pass filters at $0.1 \mathrm{~Hz}$ and low pass filters at $100 \mathrm{~Hz}$ (Order 2 Butterworth filter).Twenty electrodes were arranged on a lycra cap (EletroCap Inc., Fairfax, VA) along the frontal, temporal, parietal and occipital scalp regions, according to the $10 / 20$ International system ${ }^{21}$, and two electrodes were linked to the earlobes (bi-atrial) set as reference

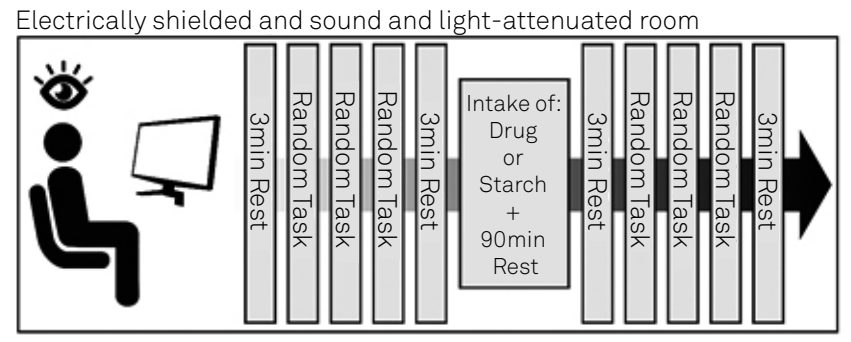

Figure 1. The experimental procedure - schematic of the tasks performed. points, yielding 20 mono-polar derivations (Fpz was used as ground electrode). Different cap sizes were used. These were placed and adjusted individually for each participant, according to the head circumference and the proportion of individual anatomy. The signal corresponding to each EEG derivation came from the electric potential difference between each electrode and the pre-set reference (earlobes). The epochs were computed according to the stimulus appearance, four seconds before and four seconds after the stimuli. There were 15 epochs for each participant before the stimuli appearance and 15 more epochs after the stimuli presentation. First, impedance levels were checked for each electrode, and were kept below $10 \mathrm{~K} \Omega$. Visual artifacts were firstly inspected with a data visualization program, using Matlab $5.3^{\circ}$ (The Mathworks, Inc.).

\section{Data processing and analysis}

EEG signals collected during the experiment were processed by a software developed by the Neurophysiology and Neuropsychology of Attention Laboratory, at the Psychiatric Institute of Universidade Federal do Rio de Janeiro, in a Matlab 5.3 environment. The Coherence value was based on the Cross and Auto Power Spectral Densities, estimated via Bartlett Periodogram for each of the 8-sec signal epochs (triggered by the target stimuli). Hence, beta coherence was obtained as the mean value of the Magnitude Squared Coherence along all frequency bins within 12 and $32 \mathrm{~Hz}$, for each considered electrode pair.

\section{Statistical analysis}

A three-way ANOVA was applied in order to identify the changes in beta coherence induced by the variable group (placebo, methylphenidate and risperidone), task (execution, action observation and motor imagery of finger movement), and moment (pre- and post-drug ingestion). When an interaction between factors was found, a Student's t-test and post hoc Scheffé test were used. A one-way ANOVA was applied to verify no statistically significant differences among the groups at the pre-drug moment. Moreover, a Bonferroni correction (7 comparisons) was applied and $\mathrm{p}$-value $(\mathrm{p} \leq 0.007)$ was considered for statistical significance. For analysis, we also considered the effect size and the degrees of freedom. The effect size was estimated as partial squared $\left(\eta^{2} p\right)$.

\section{RESULTS}

We did not find any interaction among the independent variables (i.e., group vs. task vs. moment) in none of the pairs of electrodes. Our results showed a main effect for group (Figure 2) for C3/Cz pair of electrodes [F (2)=6.299; $\mathrm{p}=0.002$; $\left.\eta^{2} \mathrm{p}=0.024\right]$ (Figure 2A; Table 1). The post hoc test demonstrated a statistical difference for risperidone when compared to placebo and methylphenidate; risperidone showed lower beta 
coherence. For $\mathrm{CZ} / \mathrm{C} 4$ pair of electrodes, we observed a main effect for task $\left[\mathrm{F}(2)=7.705 ; \mathrm{p}=0.001 ; \eta^{2} \mathrm{p}=0.030\right]$ (Figure 3A; Table 1). The post hoc test verified a statistical difference for execution task when compared to motor imagery and action observation tasks.

Moreover, we performed a one-way ANOVA to inspect group and task differences at the pre- and post-drug administration intervals, separately. We did not find differences for group nor tasks in the pre-drug administration interval. However, we found group differences at the post-administration interval for $\mathrm{C} 3 / \mathrm{CZ}$ pair of electrodes $\left[\mathrm{F}(2)=6.654 ; \mathrm{p}=0.002 ; \eta^{2} \mathrm{p}=0.049\right]$. The post hoc test demonstrated a difference between placebo vs. methylphenidate (Figure 2B; Table 2). We also found task differences at the post-drug administration interval for $\mathrm{CZ} / \mathrm{C} 4$ pair of electrodes $\left[F(2)=0.064 ; p=0.000 ; \eta^{2} p=0.065\right]$. A difference was found between execution and action observation movement (Figure 3B; Table 2).

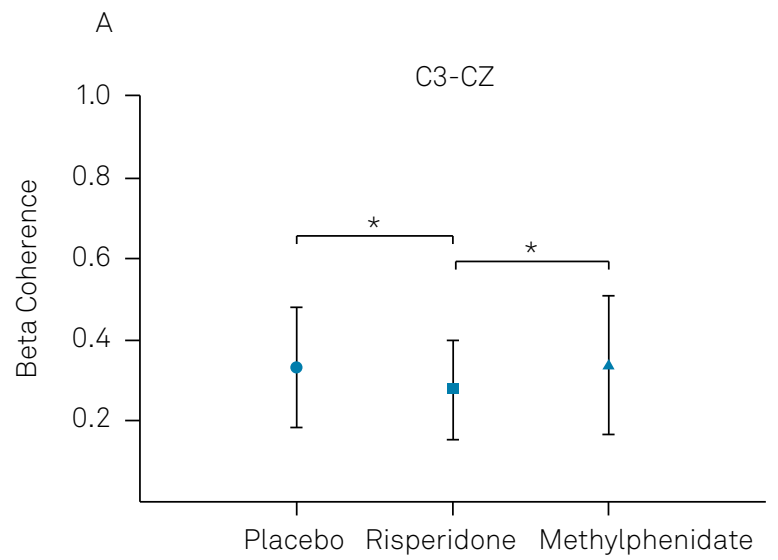

\section{Behavioral variable}

A two-way ANOVA was performed to compare the response time (from the onset of the stimulus to the completion of the movement; Reaction time + Movement time $=$ Response time) before and after drug administration in the execution task. We found an interaction effect between group

Table 1. Significant values - mean and SD related to a main effect for group and task.

\begin{tabular}{lcr}
\hline $\begin{array}{l}\text { Pairs of } \\
\text { Electrodes }\end{array}$ & Group & Task \\
\hline C3/CZ & $F(2)=6.229$, & \\
& $p=0.002$, \\
$\eta^{2} p=0.024$. & \\
& & \\
CZ/C4 & & $p(2)=7.705$, \\
& & $p=0.001$, \\
$\eta^{2} p=0.030$. \\
\hline
\end{tabular}

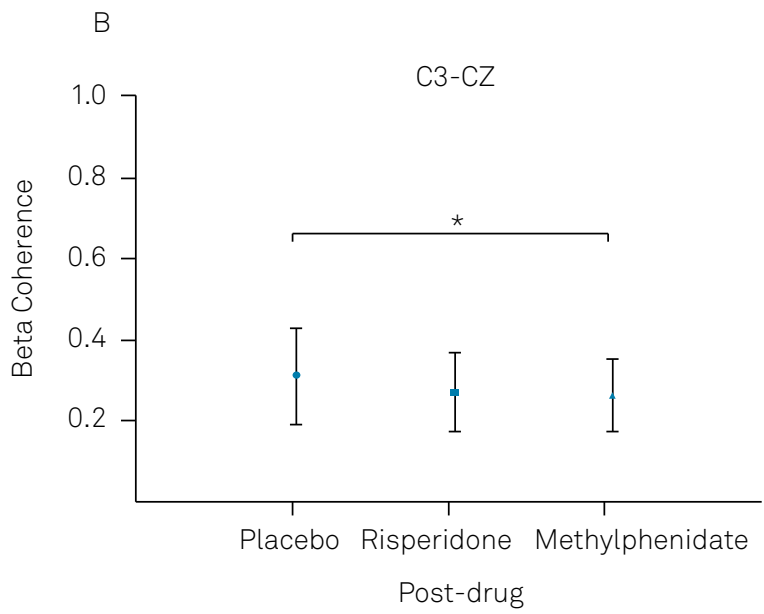

Figure 2. Main effect for group over left central area (C3-Cz). (A) Mean and standard deviation of beta coherence for the three groups investigated. (B) Mean and standard deviation of beta coherence for the three groups investigated in the post drug administration interval $(p=0.002)$.
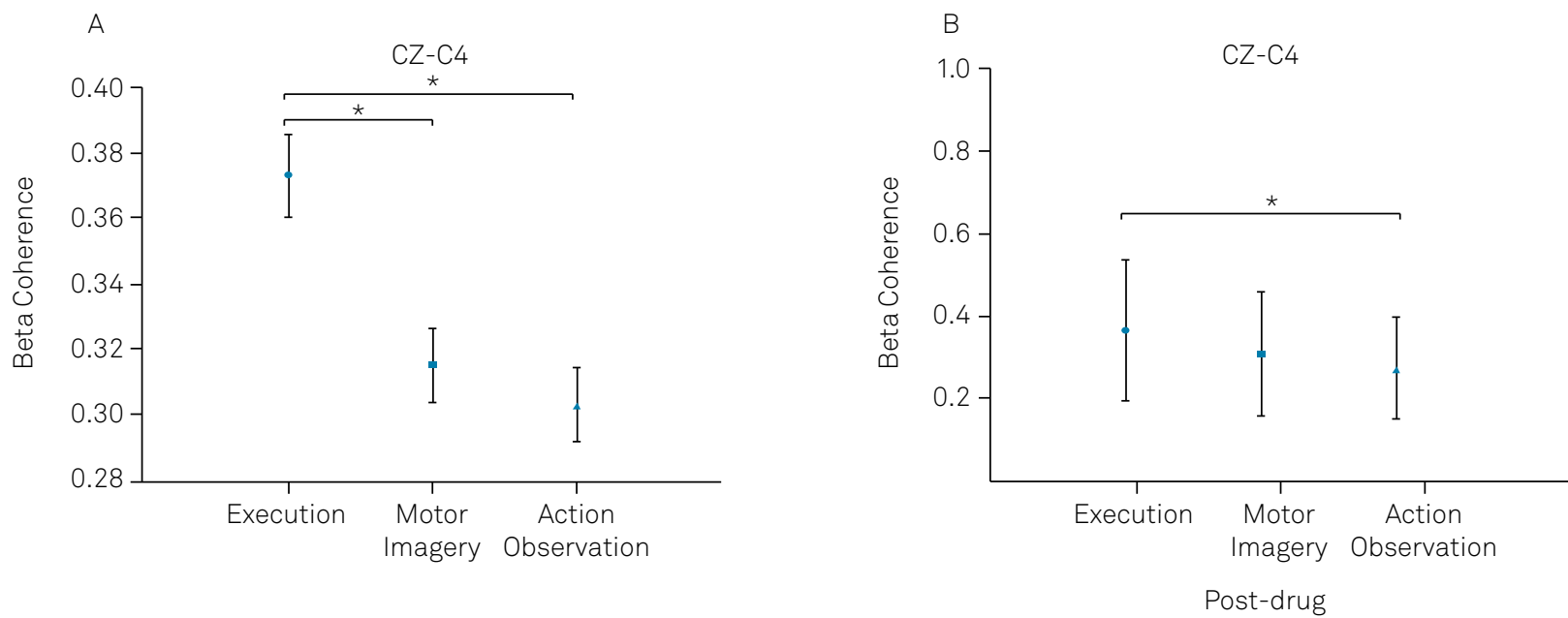

Figure 3. Mean and SD of beta coherence on central cortex (CZ-C4). (A) Main effect for Task ( $p=0.001)$. (B) Main effect for postdrug between task $(p=0.000)$. 
and moment $\left[F(2)=5.197 ; p=0.006 ; \eta^{2} p=0.006\right]$. Our results show a statistically significant difference in the reaction time for the placebo and methylphenidate groups (Figure 4).

\section{DISCUSSION}

We aimed to investigate and compare electrocortical oscillations in healthy subjects during imagination, observation and execution of a finger movement, under the influence of methylphenidate and risperidone (Figure 5). The beta rhythm is commonly observed in the somatosensory and motor cortex mapping ${ }^{22,23}$. The EEG coherence is considered an index of functional cortico-cortical connections. We hypothesized that methylphenidate would produce a higher coupling between areas, suggesting a higher somatosensory involvement, since this drug is considered a cognitive enhancer. Moreover, we presumed that the risperidone results would point out the opposite effect.

In the behavioral domain analysis, from the variables of movement time and reaction time, we showed a statistically significant difference for the placebo and methylphenidate groups. A shorter reaction time was observed in the post-placebo moment. We believe this finding is related to learning the motor task and the consolidation of information. The increase in reaction time under Methylphenidate is likely to be associated to the dose-response effect of the medication and its influence on the motor performance of healthy individuals.
Our results did not corroborate our hypothesis. We did not find an interaction among our independent variables. Our results showed a main effect for group for $\mathrm{C} 3 / \mathrm{CZ}$ pair of electrodes, and a main effect for task for $\mathrm{CZ} / \mathrm{C} 4$ pair of electrodes. These findings show that the left sensorimotor cortex is influenced by drugs and that the right sensorimotor cortex is influenced by tasks, mainly in the post-administration drug interval, thus demonstrating a hemisphere specialization regarding to drug intake. We did not find a main effect for the moment of drug administration, which suggests that the

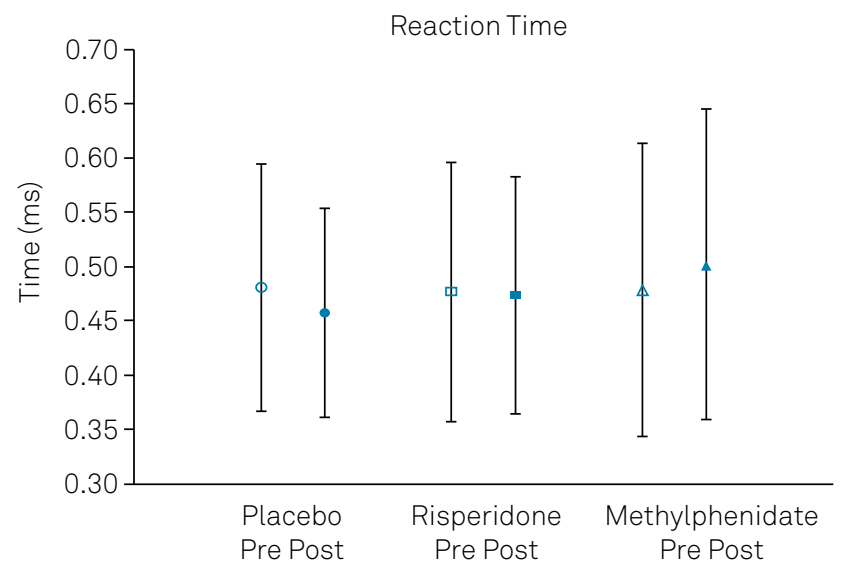

Figure 4. Mean and standard deviation of the parameter reaction time during the execution of the motor task.

The analysis revealed interaction between groups ( $p=0.006)$. Less time of reaction after placebo usage and longer time of reaction after methylphenidate usage.

Table 2. Significant values - mean and SD related to a post-drug for task.

\begin{tabular}{cccccc}
\hline & \multicolumn{2}{c}{ Mean task (SD) } & & & \\
\hline Pairs of electrodes & Execution & Motor imagery & Action observation & F-value & $p$-value \\
\hline $\mathrm{C} 3 / \mathrm{Cz}$ & $0.36(0.16)$ & $0.30(0.14)$ & $0.29(0.14)$ & $F(2)=6.654$ & 0.009 \\
$\mathrm{Cz} / \mathrm{C} 4$ & $0.37(0.17)$ & $0.31(0.13)$ & $0.30(0.14)$ & $F(2)=7.705$ & 0.001 \\
\hline
\end{tabular}

Topographical Scalp Maps

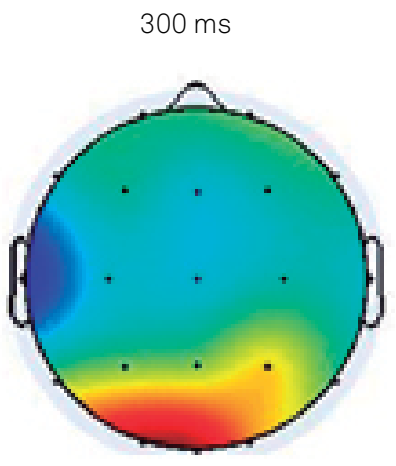

Placebo

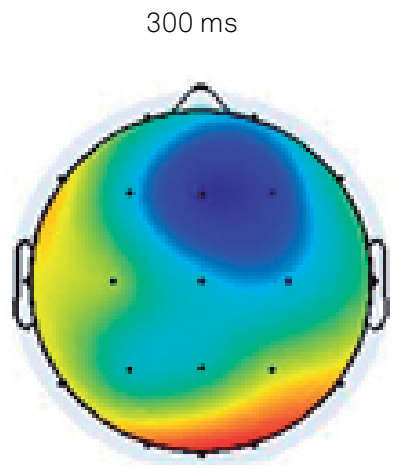

Risperidone

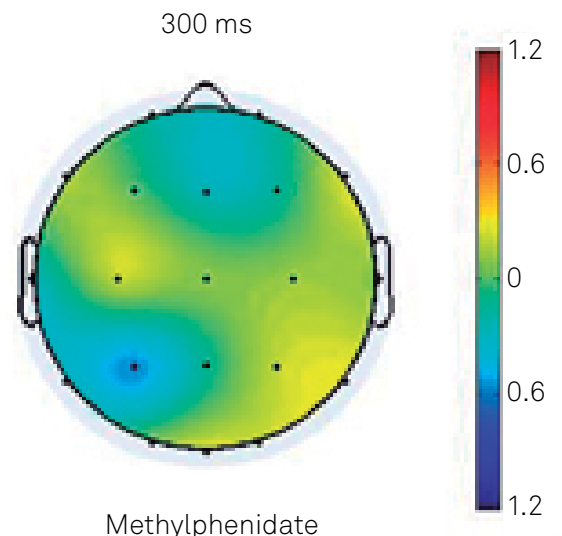

Methylphenidate

Figure 5. Topographic map showing coherence analysis of pharmaco-EEG changes induced. 
influence of dopaminergic drugs over cortico-cortical communication has some limitations.

When investigating the main effects separately, we did not find difference among groups in the pre-administration interval. This result was expected, because participants were a sample of the same population, and in the pre-administration drug interval they were not submitted to any treatment or condition. We expected differences among tasks in the pre-administration interval, with a higher functional connectivity in the executed movement followed by the observed and imagined movement. However, we did not observe differences among the tasks before the drug intake. To clarify the discussion and to focus in hemisphere specialization, we divided the discussion into two sections: left hemisphere and right hemisphere.

\section{Left hemisphere}

The central area represented by the $\mathrm{C} 3 / \mathrm{CZ}$ pair of electrodes is adjacent to the primary and somatosensory motor cortex, and it plays a fundamental role in the control, planning and execution of voluntary movements ${ }^{24}$. When we analyzed this area, risperidone group presented a lower beta coherence when compared to placebo and methylphenidate groups. However, when analyzing the pre- and postadministration interval separately, we observed a difference between placebo and methylphenidate groups in the postadministration interval. We identified a lower beta coherence for methylphenidate when compared to placebo. Contrary to our hypothesis, methylphenidate intake produced a lower beta coherence over the left primary and somatosensory motor cortex; modifying the functional coupling between $\mathrm{C} 3$ and $\mathrm{Cz}$ electrodes. Specifically, C3/Cz represents the connection between somatosensory and motor areas over the left hemisphere, area contralateral to movement and movement representation (i.e., all the subjects were right-handed). An inhibitory system would indeed be responsible for functional dissociation between cortical areas, assuming that inhibition would weaken or even predispose cortical connections $^{2}$. Hence, we supposed that the maintenance of dopamine in the synaptic cleft provokes a higher functional connectivity, which is represented by a beta coherence increase and interferes in the communication between somatosensory and motor areas. However, we found an opposite result.

Methylphenidate $(10 \mathrm{mg})$ in a single dose, in this experimental model, could not influence the motor cortex to the point of generating changes in the cortical functional coupling measurement. We believe that its action, under this dosage, on healthy men, was not enough to optimize the connection of these cortical areas, reflecting different types of demands in these regions. The reduced coherence found may be correlated to a state of lower retention of information by the cognitive-motor systems, and even a psychostimulant may interfere with cortical activity in a varied way.

\section{Right hemisphere}

We observed a higher intra-hemispheric coherence for $\mathrm{CZ} / \mathrm{C} 4$ pair of electrodes during the movement execution. We did not find differences between motor imagery and movement observation, demonstrating a prominent participation of the left hemisphere during the motor imagery. Observing the tasks in the pre- and post-administration interval separately, we identified that the tasks are different among then just in the post moment. This area is functionally related to motor preparation and execution $^{25}$. Increased coherence in this region showed a greater involvement of these functions and beta band rhythm has been related to sensorimotor integration process. This suggests that higher activity in this rhythm represents a greater coupling of neural network engaged in motor events evoked by the experiment task. Based on previous electrophysiological findings, we hypothesized that the task execution requires greater recruitment of the neural networks involved, including the ipsilateral hemisphere. Cannon et al. ${ }^{26}$ analyzed alpha and beta bands in the central electrodes during action observation and execution directed to a goal. They concluded that both reflected the mirror neurons function, but the execution allowed greater activity modulation of these bands when compared to the action observation experience.

In conclusion, our study supports other studies related to execution, motor imagery and action observation of a movement in relation to the understanding that the motor execution allows greater modulation of the beta band when compared to the others. However, it is evident that the drugs, even with antagonistic effects under the dopaminergic pathways, generate changes in the electrical activity of the somatomotor cortex. Methylphenidate, which decreased the beta activity in the motor cortex, reduces functional cortical connections. This result was interpreted as part of a cortical attentive system.

When we consider functional hemispheric asymmetry, we see an implicit assumption in the literature, highlighting the left hemisphere involved in motor tasks, whereas the right hemisphere plays a special role in mental image and action observation, due to a predominance of visuospatial and perceptual functions. Although there is this distinction, both hemispheres may be equally capable of constructing images and perceiving external stimulus, as well as being involved in the intended and observed actions. The right hemisphere showed a superiority when compared to the left hemisphere for the actions in our experiment, given the values found in coherence in beta. Cognitive aspects can influence these modulations and even the aspects of plasticity resulting from the motor task. Data were also observed in the values in the mean and standard deviation of the parameter reaction time during execution of the motor task. 


\section{References}

1. Jeannerod M. Neural simulationofaction: A unifyingmechanism for motor cognition. Neuroimage. 2001 Jul;14(2):103-9. https://doi. org/10.1006/nimg.2001.0832

2. Daronch C, Petersen RDS, Spindola MM, Vaz MA, Oliveira LF, Geremia $J M$. Bailarinas $x$ voleibolistas: efeito de diferentes treinamentos motores sobre o sinal eletroencefalográfico. Rev Bras Ciênc Esporte. 2016;38(4):384-91. http://dx.doi.org/10.1016/j.rbce.2016.02.007

3. Bastos A, Souza G, Pinto T, Souza M, Lemos T, Imbiriba L. Simulação mental de movimentos: da teoria à aplicação na reabilitação motora. Rev Neurociênc. 2014;21(4):604-19. http://dx.doi.org/10.4181/ RNC.2013.21.895.16p

4. Grush R. The emulation theory of representation: motor control, imagery, and perception. Behav Brain Sci. 2004 Jun;27(3):377-96. https://doi.org/10.1017/s0140525×04000093

5. de Lange FP, Jensen O, Bauer M, Toni I. Interactions between posterior gamma and frontal alpha/beta oscillations during imagined actions. Front Hum Neurosci. 2008 Aug;2(7):1-12. https://doi.org/10.3389/ neuro.09.007.2008

6. Brinkman L, Stolk A, Dijkerman HC, de Lange FP, Toni I. Distinct roles for alpha- and beta-band oscillations during mental simulation of goal-directed actions. J Neurosci. 2014 Oct;34(44):14783-92. https:// doi.org/10.1523/JNEUROSCI.2039-14.2014

7. Bruijn SM, Van Dieën JH, Daffertshofer A. Beta activity in the premotor cortex is increased during stabilized as compared to normal walking. Front Hum Neurosci, 2015 Oct;9(3):1-13. https://doi. org/10.3389/fnhum.2015.00593

8. Yi W, Qiu S, Qi H, Zhang L, Wan B, Ming D. EEG feature comparison and classification of simple and compound limb motor imagery. $J$ Neuroeng Rehabil. 2013 Oct 12;10:106. https://doi.org/10.1186/17430003-10-106

9. Stepp CE, Oyunerdene N, Matsuoka Y. Kinesthetic motor imagery modulates intermuscular coherence. IEEE Trans Neural Syst Rehabil Eng. 2011 Dec;19(6):638-43. https://doi.org/10.1109/ TNSRE.2011.2168982

10. Gomes MM, Infantosi AFC, Cagy M. Função de coerência: fundamentos, aplicação (e limitações) em neurologia e pesquisa (especialmente em epilepsia). Rev Bras Neurol. 2007;43:33-45.

11. Fonseca LC, Tedrus GMAS, Rezende ALRA, Giordano HF, Rezende ALRA, Giordano HF. Coherence of brain electrical activity: a quality of life indicator in Alzheimer's disease? Arq Neuropsiquiatr. 2015;73(5):396-401. http://dx.doi.org/10.1590/0004-282X20150035

12. Jurkiewicz MT, Gaetz WC, Bostan AC, Cheyne D. Post-movement beta rebound is generated in motor cortex: evidence from neuromagnetic recordings. Neuroimage. 2006 Sep;32(3):1281-9. https://doi. org/10.1016/j.neuroimage.2006.06.005

13. Toni I, Thoenissen D, Zilles K. Movement preparation and motor intention: an event-related fMRI study. J Neurosci. 2002;22:9248-9260.
14. Hughes M, Lynch P, Rhodes J, Yates REA. Electroencephalographic and psychomotor effects of chlorpromazine and risperidone relative to placebo in normal healthy volunteers. J Clin Pharmacol. 1999 Sep;48(3):323-30. https://doi.org/10.1046/j.1365-2125.1999.00021.x

15. Chen W, Xiao Q, Shao M, Feng T, Liu WG, Luo XG, et al. Prevalence of wearing-off and dyskinesia among the patients with Parkinson's disease on levodopa therapy: a multi-center registry survey in mainland China. Transl Neurodegener. 2014 Dec 5;3(1):26. https://doi. org/10.1186/2047-9158-3-26

16. Coelho L, Chaves E, Vasconcelos S, Fonteles M, Sousa F, Viana G. Transtorno do Déficit de Atenção e Hiperatividade (TDAH) na criança. Aspectos Neurobiológicos, Diagnóstico e Conduta Terapêutica. Acta Med Port. 2010;23(4):689-96.

17. Stray LL, Stray T, Iversen S, Ruud A, Ellertsen B. Methylphenidate improves motor functions in children diagnosed with hyperkinetic disorder. Behavioral and Brain Functions. 2009;5(21):1-12. https://doi. org/10.1186/1744-9081-5-21

18. Oldfield R. The assessment and analysis of handedness: the Edinburgh inventory. Neuropsychologia. 1971;9(1):97-113. https://doi. org/10.1016/0028-3932(71)90067-4

19. Gualberto Cremades J. The effects of imagery perspective as a function of skill level on alpha activity. Int J Psychophysiol. 2002 Mar;43(3):261-71. https://doi.org/10.1016/s0167-8760(01)00186-6

20. Stecklow MV, Infantosi AFC, Cagy M. Changes in the electroencephalogram alpha band during visual and kinesthetic motor imagery. Arq Neuropsiquiatr. 2007;65(4A):1084-8. https://doi. org/10.1590/S0004-282X2007000600034

21. Klem GH, Lüders HO,Jasper HH, Elger C. The ten-twenty electrode system of the International Federation. The International Federation of Clinical Neurophysiology. Electroencephalogr Clin Neurophysiol Suppl. 1999;52:3-6.

22. Fortuna M, Teixeira S, Machado S, Velasques B, Bittencourt J, Peressutti $\mathrm{C}$, et al. Cortical Reorganization after Hand Immobilization: The beta qEEG Spectral Coherence Evidences. PloS ONE. 2013;8(11):79912. https://doi.org/10.1371/journal.pone.0079912

23. Fortunato S, Tanaka GK, Araújo F, Bittencourt J, Aprigio D, Gongora $\mathrm{M}$, et al. The effects of bromazepam over the central and frontal areas during a motor task: an EEG study. Arq Neuropsiquiatr, 2015 Apr;73(4):321-9. http://dx.doi.org/10.1590/0004-282X20150011

24. Velasques B, Machado S, Portella CE, Silva JG, Basile LF, Cagy M, et al. Electrophysiological analysis of a sensorimotor integration task. Neurosci Lett. 2007 Oct 22;426(3):155-9. https://doi.org/10.1016/j.neulet.2007.08.061

25. Chouinard AP, Paus T. The primary motor and premotor areas of the human cerebral cortex. Neuroscientist. 2006 Apr;12(2):143-52. https://doi.org/10.1177/1073858405284255

26. Cannon EN, Yoo KH, Vanderwert RE, Ferrari PF, Woodward AL, Fox NA. Action experience, more than observation, influences mu rhythm desynchronization. PLoS One. 2014 Mar 24;9(3):e92002. https://doi. org/10.1371/journal.pone.0092002 